\title{
Role of signal transduction crosstalk between adenylyl cyclase and MAP kinase in hippocampus-dependent memory
}

\author{
Zhengui $\mathrm{Xia}^{1}$ and Daniel R. Storm ${ }^{2,3}$ \\ ${ }^{1}$ Toxicology Program in the Department of Environmental and Occupational Health Sciences, University of Washington, Seattle, \\ Washington 98195, USA; ${ }^{2}$ Department of Pharmacology, University of Washington, Seattle, Washington 98195, USA
}

\begin{abstract}
One of the intriguing questions in neurobiology is how long-term memory (LTM) traces are established and maintained in the brain. Memory can be divided into at least two temporally and mechanistically distinct forms. Short-term memory (STM) lasts no longer than several hours, while LTM persists for days or longer. A crucial step in the generation of LTM is consolidation, a process in which STM is converted to LTM. Hippocampus-dependent LTM depends on activation of $\mathrm{Ca}^{2+}$, Erk/MAP kinase (MAPK), and cAMP signaling pathways, as well as de novo gene expression and translation. One of the transcriptional pathways strongly implicated in LTM is the CREB/CRE (calcium, CAMP response element) transcriptional pathway. Interestingly, this transcriptional pathway may also contribute to other forms of neuroplasticity including adaptive responses to drugs. Evidence discussed in this review indicates that activation of the Erkl/2 MAP Kinase (MAPK)/ CRE transcriptional pathway during the formation of hippocampus-dependent memory depends on calmodulin (CaM)stimulated adenylyl cyclases.
\end{abstract}

\section{Activation of the CREB/CRE transcriptional pathway is necessary for hippocampus-dependent LTM}

The calcium, cAMP response element (CRE) has several properties that implicate it in long-term memory (LTM). The CRE can integrate elevated $\mathrm{Ca}^{2+}$ and cAMP signals (Impey et al. 1998b), and the CRE-binding protein (CREB) is hypothesized to be a key regulator of LTM. CREB is obligatory for long-term facilitation in Aplysia (Dash et al. 1990; Martin et al. 1997) as well as LTM in Drosophila (Yin et al. 1994, 1995) and mice (Bourtchuladze et al. 1994; Pittenger et al. 2002). In addition, CRE-mediated transcription is activated during L-LTP (long-lasting long-term potentiation) (Impey et al. 1996), a form of transcriptionally dependent LTP proposed as a model for LTM (Frey et al. 1993; Nguyen and Kandel 1996). Using a CRE-LacZ reporter mouse strain, it was discovered that CRE-mediated transcription is activated (Fig. 1) and CREB is phosphorylated on Ser-133 in area CA1 and CA3 of the hippocampus after training for contextual and passive avoidance memory formation (Impey et al. 1998a). CREB is also phosphorylated at Ser-133 in the hippocampus when mice are trained for novel objects (Wang et al. 2004). Furthermore, the traininginduced expression of CRE-mediated transcription depends on NMDA receptor and MAPK activities (Athos et al. 2002). Moreover, Alberini's laboratory discovered that training for an inhibitory avoidance task also increases CREB phosphorylation at Ser-133 (Taubenfeld et al. 1999).

To test whether increases in CRE-mediated gene expression in area CA1 of the hippocampus are obligatory for contextual memory formation, cannulated mice were bilaterally infused before behavioral training with either a CRE decoy oligonucleotide or control oligonucleotide of the same composition with a scrambled sequence (Athos et al. 2002). When tested later, CRE decoy-treated mice display no memory for context and behave like naive ani-

${ }^{3}$ Corresponding author

E-mail dstorm@u.washington.edu

Article is online at http://www.learnmem.org/cgi/doi/10.1101/lm.027128.112. mals. This study demonstrated that increased expression of one or more genes through CRE-mediated transcription is required for contextual memory. This experiment was inspired by a study performed by Dash and Kandel, who showed that injection of a CRE oligonucleotide into the nucleus of Aplysia sensory neurons blocks long-term facilitation (Dash et al. 1990). Interestingly, training for inhibitory avoidance memory stimulates the expression of the transcription factor CCAAT enhancer binding protein (C/EBP), a CRE-regulated gene product (Taubenfeld et al. 2001).

\section{Mechanisms for $\mathrm{Ca}^{2+}$ stimulation of the CREB/CRE transcriptional pathway}

How does $\mathrm{Ca}^{2+}$ stimulate CRE-mediated transcription in neurons? Several kinases can activate CREB by catalyzing its phosphorylation at Ser-133. Synaptic activity and $\mathrm{Ca}^{2+}$ influx trigger an early and transient phase of CREB phosphorylation, which is mediated by CaM kinase IV (CaMKIV) (Bito et al. 1996; Wu et al. 2001), as well as a persistent phase of phosphorylation ( $>5 \mathrm{~min}$ ) mediated by MAPK signaling (Impey et al. 1998b). In vivo studies performed in mice indicate that activation of MAPK, mitogen and stress-activated kinase 1 (MSK-1), and CREB during memory formation is dependent on CaM-stimulated adenylyl cyclase activity (Sindreu et al. 2007). When mice are trained for contextual memory formation, MAPK is activated and undergoes nuclear translocation in area CA1 of the hippocampus (Sindreu et al. 2007).

\section{Role of $\mathrm{Ca}^{2+}$-stimulated adenylyl cyclases in LTM}

Eight of the known adenylyl cyclases are expressed in the hippocampus (for reviews, see Poser and Storm 2001; Wang and Storm 2003). Of these, only type 1 adenylyl cyclase (AC1) and type 8 adenylyl cyclase (AC8) are stimulated by $\mathrm{CaM}$ and $\mathrm{Ca}^{2+}$. AC1 is neurospecific (Xia et al. 1993) and is expressed in the hippocampus (DG, CA1-CA3), neocortex, entorhinal cortex, cerebellar cortex, and the olfactory system (Xia et al. 1991). To evaluate 
A
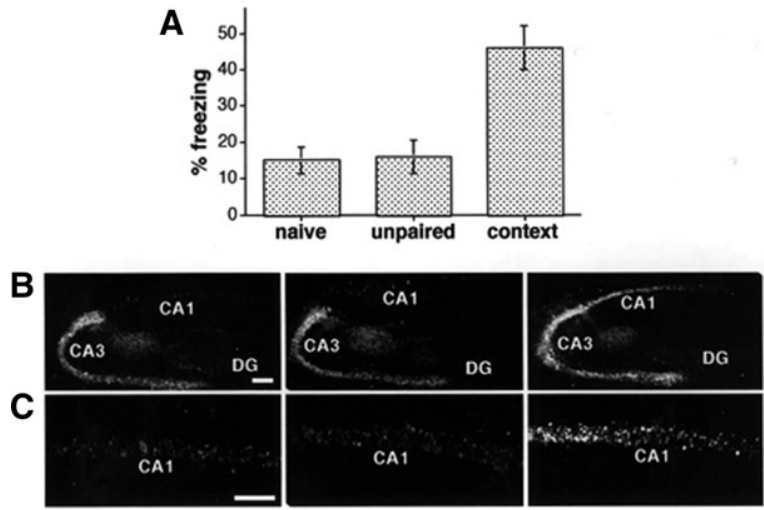

Figure 1. CRE-mediated transcription is activated in the hippocampus when mice are trained for contextual memory. (A) Summary of associative learning measured $8 \mathrm{~h}$ after training for contextual fear memory. Mean percentage of time spent freezing in the conditioning chamber is depicted for naive, unpaired control, and context-trained mice (naive, $n=7$; unpaired, $n=8$; context-trained, $n=23$; naive vs. context and unpaired vs. context, $P<0.0005)$. (B) Low-magnification confocal images showing CRE-regulated LacZ immunostaining in hippocampal slices from representative naive unpaired control and context-trained mice. Scale bar, $500 \mathrm{~m}$. (C) Higher-magnification images of the CA1 region from representative naive, unpaired control, and context-trained mice. Scale bar, $100 \mu \mathrm{m}$. (Reprinted from Impey et al. 1998a.)

the physiological functions of $\mathrm{AC} 1$, the $A C 1$ gene was disrupted in mice (Wu et al. 1995). AC1 mutant mice show deficiencies in mossy fiber LTP (Villacres et al. 1998) and cerebellar LTP (Storm et al. 1998). Mice lacking either AC1 or AC8 exhibit L-LTP and normal contextual and passive avoidance memory. Consequently, transgenic mice lacking both AC1 and AC8 (double-knockout, DKO mice) were examined for L-LTP and LTM (Wong et al. 1999). Although $\mathrm{AC} 1^{-/-}$and $\mathrm{AC} 8^{-/-}$mice exhibit L-LTP and LTM for fear conditioning, DKO mice do not. To determine if the defect in passive avoidance LTM is due to a loss of cAMP increases in the hippocampus, DKO mutant mice were cannulated to deliver forskolin, a general adenylyl cyclase activator. Administration of forskolin to area CA1 right before training restored normal LTM. This indicates that $\mathrm{Ca}^{2+}$-stimulated adenylyl cyclase activity is essential for LTM, and that either AC1 or AC8 can generate the critical cAMP signal. More recently, it was discovered that memory for social recognition (Garelick et al. 2009) as well as the persistence of remote contextual memory are also dependent on CaM-stimulated adenylyl cyclases (Shan et al. 2008).

Although it was known that CaM-stimulated adenylyl cyclases (Wu et al. 1995; Wong et al. 1999) and MAPK (Atkins et al. 1998; Blum et al. 1999) are critical for hippocampus-dependent memory, the extent of coactivation and crosstalk between these pathways in the same subset of neurons during fear conditioning had not been described. Using confocal imaging of hippocampus sections from trained and untrained mice, it was discovered that MAPK is activated in the nucleus and at the synapse of CA1 pyramidal neurons (Sindreu et al. 2007). Furthermore, PKA and MAPK are coactivated in a subset of hippocampal CA1 pyramidal neurons following contextual fear conditioning. Using transgenic mice lacking both AC1 and AC8, it was demonstrated that activation and nuclear translocation of MAPK during formation of contextual memory is dependent on CaM-stimulated adenylyl cyclase activity. Furthermore, there was a strong correlation between stimulation of MAPK and MSK-1, a downstream CREB kinase. These data support the hypothesis that activation of CaM-stimulated adenylyl cyclase activity is critical for memory formation because cAMP supports the nuclear translocation and activation of MAPK and hence the stimulation of CREB-mediated transcription (Fig. 2).

Although data from several laboratories support the hypothesis that CaM-stimulated adenylyl cyclase and MAPK are required for consolidation of hippocampus-dependent memory, memory formation also depends on several other signaling events. Synaptic activity-induced CREB phosphorylation does not always result in transcriptional activation (Deisseroth et al. 1996; Impey et al. 1998b; Liu and Graybiel 1996; Fields et al. 1997), suggesting that full activation of CREB-dependent transcription depends on other events. For example, NMDA activates transcription of CREB-responsive genes in primary hippocampal neurons, with CaMKIV responsible for phosphorylating the CREB coactivator, CBP, at Ser-301 (Impey et al. 2002). Furthermore, CaM kinase II plays a major role in memory (Bach et al. 1995) and is important for behavioral plasticity (Miller et al. 2002). Other enzymes implicated in the formation and maintenance of memory includes PKM $\zeta$ (Sacktor 2011) and DNA methylases (Sweatt 2010).

\section{Circadian oscillation of cAMP and MAPK activity in the hippocampus depends on calmodulin-stimulated adenylyl cyclase activity}

Several studies have implicated the circadian rhythm in memory consolidation. For example, circadian phase shifting following training interferes with the retention of the hippocampusdependent Morris water maze task (Devan et al. 2001) and also causes retrograde amnesia for hippocampus-dependent passive avoidance memory (Tapp and Holloway 1981). Furthermore, lesions of the suprachiasmatic nucleus (SCN) decrease hippocampus-dependent LTM in rodents (Stephan and Kovacevic 1978). Aplysia also undergo circadian oscillations in long-term sensitization (Fernandez et al. 2003). Moreover, there are additional studies in several species suggesting that circadian rhythm may play a critical role in memory consolidation (Maury and Queinnec 1992; Leirer et al. 1994; Chaudhury and Colwell 2002).

Because of research implicating circadian rhythm in memory consolidation, we examined the activity of MAPK during the circadian cycle (Eckel-Mahan et al. 2008). MAPK and $\mathrm{Ca}^{2+}$-stimulated adenylyl cyclase activities undergo a circadian oscillation in

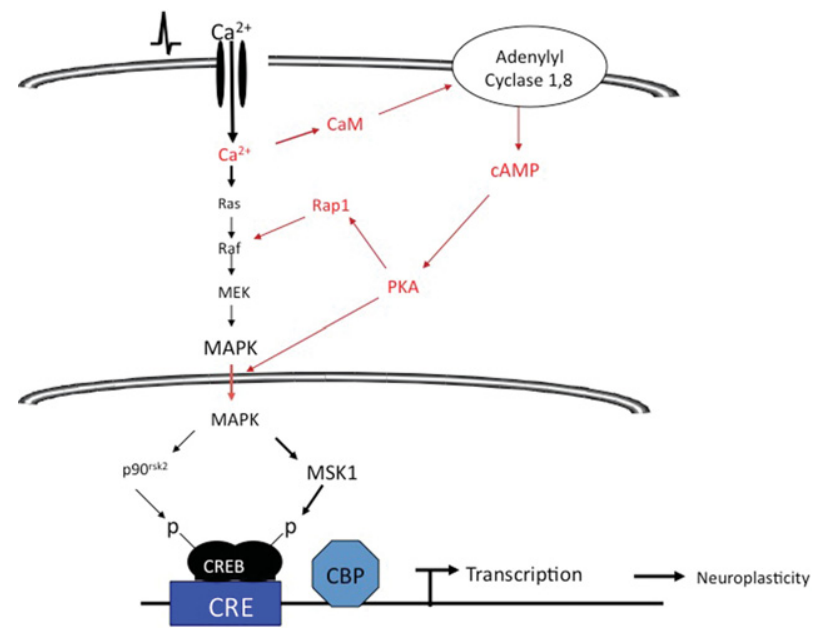

Figure 2. It is hypothesized that $\mathrm{Ca}^{2+}$ increases generated during formation of hippocampus-dependent memory activate CaM-stimulated adenylyl cyclases and that this CAMP signal supports the activation and nuclear translocation for MAPK and subsequent stimulation of CREB-mediated transcription through MSK1. 


\section{2- $\mathrm{hr}$ light/12-hr dark cycle}
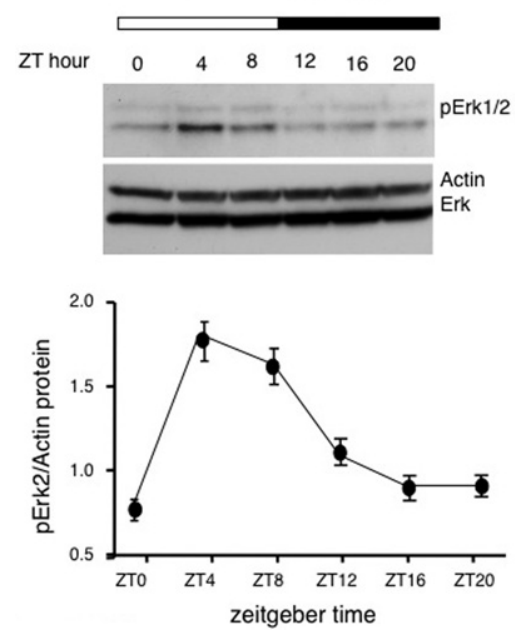

Figure 3. MAPK activity undergoes a circadian oscillation in the hippocampus. Phosphorylation of MAPK oscillates in the hippocampus on the diurnal cycle. Mice were maintained on a 12-h light/12-h dark cycle for at least $10 \mathrm{~d}$ before experimentation. Mice were sacrificed every $4 \mathrm{~h}$. Sacrifices made during the dark cycle were performed under red light. Pooled hippocampal extracts were evaluated by Western blot for phospho-p42MAPK expression. Phospho-P42/MAPK was normalized to actin expression in the hippocampus during the diurnal cycle $(n=3$ animals per time point). ANOVA error bars, SE (Bonferroni's Multiple Comparison Test for post hoc analysis). (Reprinted from Eckel-Mahan et al. 2008.)

the hippocampus (Figs. 3, 4) that is paralleled by changes in Ras activity as well as the phosphorylation of MEK1 and CREB (Fig. 5; Eckel-Mahan et al. 2008). The nadir of this activation cycle corresponds with severe deficits in hippocampus-dependent fear conditioning, under both diurnal and free-running conditions. Furthermore, circadian oscillations in cAMP and MAPK activity are absent in DKO mice, suggesting that cAMP controls the oscillation of MAPK (Fig. 6). Disruption of this oscillation by administration of MEK inhibitors at the peak of MAPK activity blocks the oscillation of MAPK and impairs the maintenance of contextual memory. Furthermore, disruption of the MAPK oscillation by exposure of the mice to constant light conditions also impairs memory persistence. Administration of forskolin, an adenylyl cyclase activator, during the night when cAMP levels are lowest in mice impairs memory. These data suggest that the persistence of long-term memories may depend on reactivation of the cAMP/MAPK/CREB transcriptional pathway in the hippocampus during the circadian cycle and that oscillations in $\mathrm{Ca}^{2+}$-sensitive adenylyl cyclase activity may drive the circadian oscillation of the MAPK pathway. This suggests that that the expression or activity of AC1 and/or AC8 may undergo a circadian oscillation in the hippocampus.

Is the circadian oscillation of adenylyl cyclase and MAPK activities intrinsic to the hippocampus or is it driven by the master circadian clock in the suprachiasmatic nucleus (SCN)? To address this question, the SCN of mice was ablated by electrolytic lesion, and the mice were examined for hippocampus-dependent memory as well as adenylyl cyclase and MAPK activities (Phan et al. 2011). Electrolytic lesion of the SCN $2 \mathrm{~d}$ after training for contextual fear memory reduces contextual memory measured $2 \mathrm{wk}$ after training, indicating that maintenance of contextual memory depends on the SCN. Spatial memory measured in the Morris water maze is also compromised in SCN-lesioned mice. Moreover, the circadian oscillation of adenylyl cyclase and MAPK activities in the hippocampus is destroyed by lesioning of the SCN. These data support the hypothesis that hippocampus-dependent longterm memory is dependent on the SCN-controlled oscillation of the adenylyl cyclase/MAPK pathway/CRE-mediated transcriptional pathway in the hippocampus.

\section{Can memory be enhanced by a genetic increase in $\mathrm{ACl}$ activity?}

On the basis of the studies described above, it was hypothesized that pharmacological or genetic increases in cAMP signaling in the hippocampus may augment memory, if the cAMP increases are not chronically elevated throughout the brain. To test this idea, hippocampus-dependent memory was examined in two different transgenic mouse strains in which adenylyl cyclase activity was increased. In the first case, mice in which the gene for $G_{i \alpha 1}$ was ablated were examined. Genetic ablation of $\mathrm{G}_{\mathrm{i} \alpha 1}$ by gene disruption causes a significant increase in hippocampal adenylyl cyclase activity and enhanced LTP in area CA1 (Pineda et al. 2004). Furthermore, gene ablation of $\mathrm{G}_{\mathrm{i} \alpha 1}$ or antisense oligonucleotidemediated depletion of $G_{i \alpha 1}$ disrupted hippocampus-dependent memory. This suggested that $\mathrm{G}_{\mathrm{i} \alpha 1}$ provides a critical mechanism for tonic inhibition of adenylyl cyclase activity in the hippocampus. The loss of $G_{i \alpha 1}$ may amplify the responsiveness of CA1 postsynaptic neurons to stimuli that strengthen synaptic efficacy, thereby diminishing synapse-specific plasticity required for new memory formation. In other words, general nonspecific increases in cAMP across the hippocampus or other areas of brain may lead to saturation and memory defects. Furthermore, bilateral infusion of Sp-cAMP, a PKA activator into the prefrontal cortex, impairs working memory providing additional evidence to that that general increases in cAMP and PKA activity in various regions of the brain can impair memory (Taylor et al. 1999; Wang et al. 2007).

Because of the memory defects observed when $G_{i \alpha 1}$ was ablated in the hippocampus, transgenic mice in which AC1 was overexpressed using the CaM kinase $2 \alpha$ promoter were generated (Mayford et al. 1996) to restrict increased adenylyl cyclase to the forebrain (Wang et al. 2004). Since AC1 is a $\mathrm{Ca}^{2+}$-stimulated adenylyl cyclase, the largest cAMP increases in the $\mathrm{AC}^{+}$mice would occur during synaptic-specific, activity-dependent increases in intracellular $\mathrm{Ca}^{2+}$. AC1 ${ }^{+}$mice show elevated LTP, increased memory for novel objects (Wang et al. 2004), and social recognition (Garelick et al. 2009) as well as more persistent remote contextual memory (Shan et al. 2008). However, the rate of

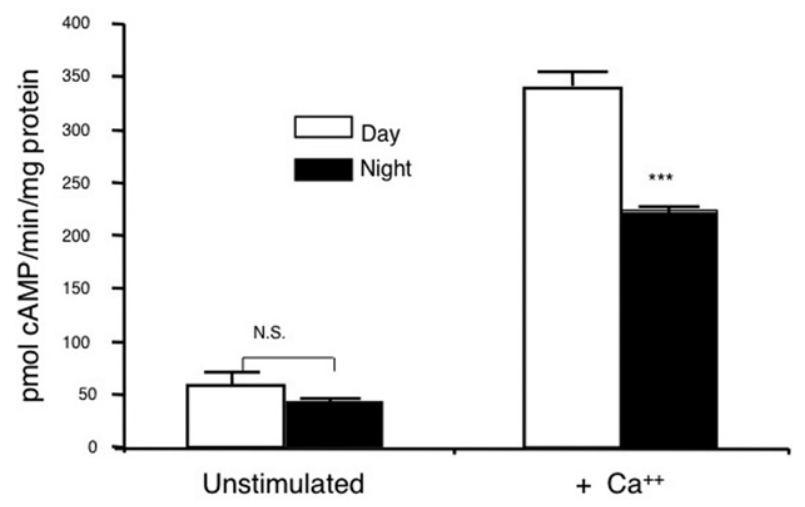

Figure 4. There is more membrane calcium-stimulated adenylyl cyclase activity during the day than during the night. Adenylyl cyclase activity expressed in picomoles of CAMP/minute per milligram of protein from pooled hippocampi excised at ZT8 (day) and ZT20 (night) stimulated with $7 \mu \mathrm{M}$ free calcium. (Adapted from Eckel-Mahan et al. 2008.) 
A

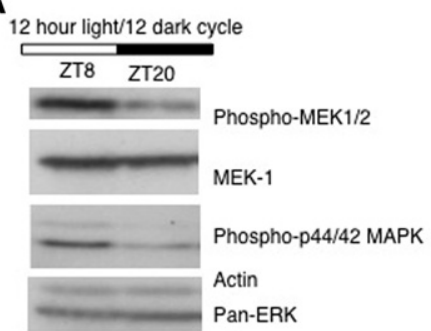

C

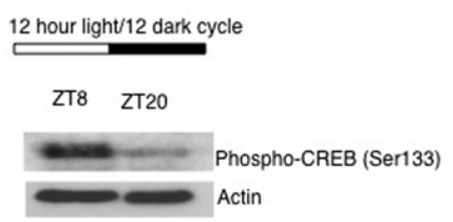

B

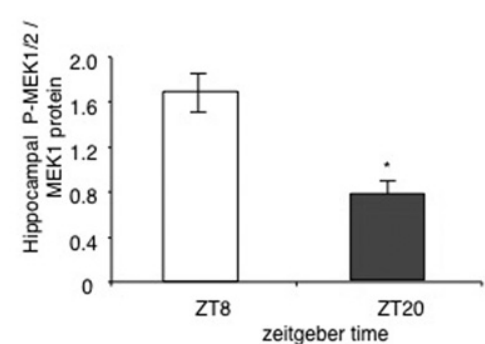

D

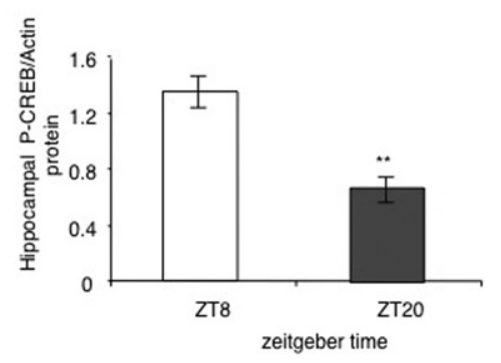

Figure 5. MEK activity and P-CREB undergo a circadian oscillation in the hippocampus. (A) P-MEK-1/ 2 expression in pooled hippocampal extracts from animals dissected at ZT8 or ZT20. (B) Quantification of P-MEK-1 $/ 2$ at ZT8 and ZT20 normalized to MEK- 1 protein expression. ( $n=5$ animals per time point). $\left.{ }^{*}\right) P=0.019$, two-tailed $t$-test; error bars, SE. (C) P-CREB expression in pooled hippocampal extracts from animals dissected at ZT8 or ZT20. (D) Quantification of P-CREB phosphorylation at ZT8 and ZT20 ( $n=4-5$ animals per time point). $\left.{ }^{* *}\right) P<0.001$; two-tailed $t$-test; error bars, SE. (Adapted from Eckel-Mahan et al. 2008.)

contextual memory extinction is reduced in $\mathrm{AC}^{+}$mice consistent with studies showing that memory extinction is impaired in CB1-receptor knockout mice (Marsicano et al. 2002), another transgenic mouse strain that probably has elevated adenylyl cyclase activity in the hippocampus.

To determine if increasing AC1 expression improves memory when older mice are trained, fear, recognition, and spatial memory in mice aged to 25 mo were examined (Garelick et al. 2009). Young adult AC1 ${ }^{+}$ mice have enhanced social recognition memory, and normal fear as well as spatial memory. Surprisingly, aged $\mathrm{AC}^{+}$ mice had poorer spatial memory than age-matched wild-type littermates, a defect not seen with young $\mathrm{AC}^{+}$mice. There was no effect on contextual or passive avoidance memory of old mice. These data suggest that the decrease in $\mathrm{Ca}^{2+}$ - stimulated adenylyl cyclase activity during aging of wild-type mice may be an adaptive mechanism required to maintain spatial memory function. This may be due to the fact that $\mathrm{Ca}^{2+}$ influx through L-type voltage gated calcium channels in the hippocampus increases with age (Campbell et al. 1996; Thibault and Landfield 1996), and clearance of internal $\mathrm{Ca}^{2+}$ decreases with aging (Toescu and Verkhratsky 2007). Therefore, $\mathrm{Ca}^{2+}$ stimulation of cAMP through activation of AC1 may lead to excessive cAMP levels that impair memory formation in old mice but not young mice.

Data obtained with the $\mathrm{AC}^{+}$mice suggest that AC1 or AC8 may be useful drug target sites for enhancement of
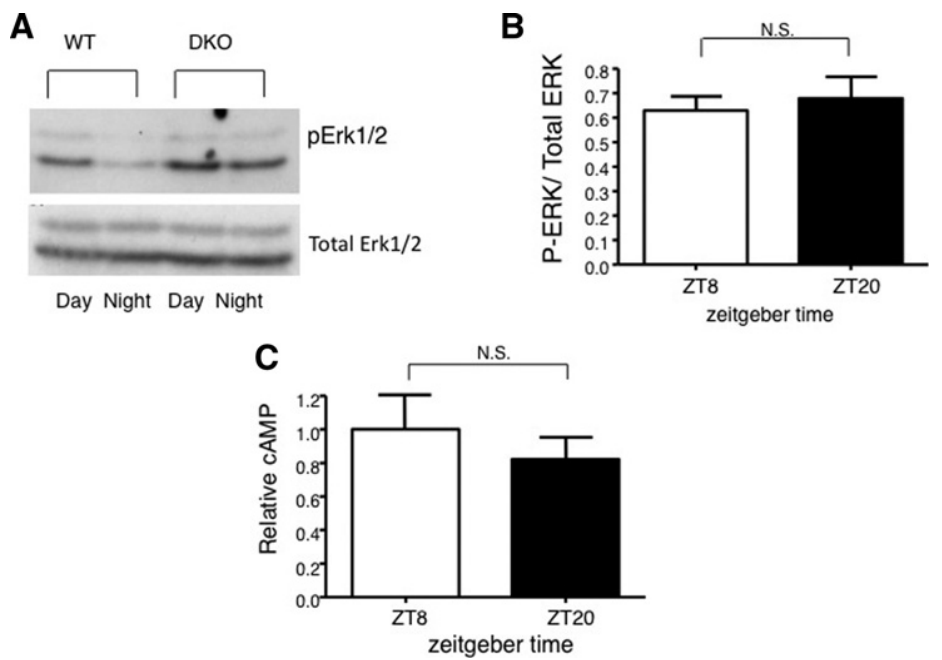

Figure 6. AC1 / AC8 double-knockout mice do not exhibit diurnal oscillations in pErk activity or CAMP in the hippocampus. (A) pMEK1/2, MEK1, pErk1/2, actin, and total Erk protein in pooled wild-type (WT) and DKO hippocampal tissue taken at ZT8 or ZT20. (B) Quantification of pErk relative to Erk expression in DKO animals. Two-tailed $t$-test; error bars, $\mathrm{SE}(n=10$ for each genotype, $n=5$ per time point). (C) Quantification of the fold change in CAMP accumulation in DKO hippocampus at ZT8 and $Z$ T20. $P=0.1300$. Two-tailed $t$-test; error bars, $S E$ (error derived from four experiments, three hippocampal lobes pooled per time point per experiment). (Adapted from Eckel-Mahan et al. 2008.) 
mediated transcriptional pathway in the hippocampus. Calciumsensitive adenylyl cyclases are required for memory consolidation because they provide a cAMP signal during training that is required for the activation and nuclear translocation of MAPK during memory formation as well as the circadian oscillation of MAPK activity in the hippocampus. Drugs that activate AC1 when it is stimulated by synaptic specific, activity-dependent $\mathrm{Ca}^{2+}$ increases may enhance memory, specifically when applied during the rest phase of the circadian cycle.

\section{Acknowledgments}

We thank two anonymous referees for constructive comments. This project was supported by the National Institutes of Health (AG19193 to Z.X. and MH073601 NS 20498 to D.R.S.).

\section{References}

Athos J, Impey S, Pineda V, Chen X, Storm D. 2002. Hippocampal CRE-mediated gene expression is required for contextual memory formation. Nat Neurosci 5: 1119-1120.

Atkins CM, Selcher JC, Petraits JJ, Trzaskos JM, Sweatt JD. 1998. The MAPK cascade is required for mammalian associative learning. Nat Neurosci 1: 602-609.

Bach ME, Hawkins RD, Osman M, Kandel ER, Mayford M. 1995 Impairment of spatial but not contextual memory in CaMKII mutant mice with a selective loss of hippocampal LTP in the range of the theta frequency. Cell 81: 905-915.

Bito H, Deisseroth K, Tsien RW. 1996. CREB phosphorylation and dephosphorylation: $\mathrm{A} \mathrm{Ca}^{2+}$ - and stimulus duration-dependent switch for hippocampal gene expression. Cell 87: 1203-1214.

Blum S, Moore AN, Adams F, Dash PK. 1999. A mitogen-activated protein kinase cascade in the CA1/CA2 subfield of the dorsal hippocampus is essential for long-term spatial memory. J Neurosci 19: 3535-3544.

Bourtchuladze R, Frenguelli B, Blendy J, Cioffi D, Schutz G, Silva AJ. 1994 Deficient long-term memory in mice with a targeted mutation of the cAMP-responsive element-binding protein. Cell 79: 59-68.

Campbell LW, Hao SY, Thibault O, Blalock EM, Landfield PW. 1996. Aging changes in voltage-gated calcium currents in hippocampal CA1 neurons. J Neurosci 16: 6286-6295.

Chaudhury D, Colwell CS. 2002. Circadian modulation of learning and memory in fear conditioned mice. Behav Brain Res 133: 95-108.

Dash PK, Hochner B, Kandel ER. 1990. Injection of the cAMP-responsive element into the nucleus of Aplysia sensory neurons blocks long-term facilitation. Nature 345: 718-721.

Deisseroth K, Bito H, Tsien RW. 1996. Signaling from synapse to nucleus: Postsynaptic CREB phosphorylation during multiple forms of hippocampal synaptic plasticity. Neuron 16: 89-101.

Devan BD, Goad EH, Petri HL, Antoniadis EA, Hong NS, Ko CH, Leblanc L, Lebovic SS, Lo Q, Ralph MR, et al. 2001. Circadian phase-shifted rats show normal acquisition, but impaired long-term retention of place information in the water task. Neurobiol Learn Mem 75: 51-62.

Eckel-Mahan K, Phan T, Han S, Wang H, Chan G, Scheiner Z, Storm D. 2008. Circadian oscillation of MAPK activity and cAMP in the hippocampus: Implications for memory persistence. Nat Neurosci 11: 1074-1082.

Fernandez RI, Lyons LC, Levenson J, Khabour O, Eskin A. 2003. Circadian modulation of long-term sensitization in Aplysia. Proc Natl Acad Sci 100: $14415-14420$

Fields RD, Eshete F, Stevens B, Itoh K. 1997. Action potential-dependent regulation of gene expression: Temporal specificity in $\mathrm{Ca}^{2+}$ cAMP-responsive element binding proteins, and mitogen-activated protein kinase signaling. J Neurosci 17: 7252-7266.

Frey U, Huang YY, Kandel ER. 1993. Effects of cAMP simulate a late stage of LTP in hippocampal CA1 neurons. Science 260: 1661-1664.

Garelick MG, Chan G, Dirocco DP, Storm DR. 2009. Overexpression of Type I adenylyl cyclase in the forebrain impairs spatial memory in aged but not young mice. J Neurosci 29: 10835-10842.

Impey S, Mark M, Villacres EC, Poser S, Chavkin C, Storm DR. 1996. Induction of CRE-mediated gene expression by stimuli that generate long-lasting LTP in area CA1 of the hippocampus. Neuron 16: 973-982.

Impey S, Smith DM, Obrietan K, Donahue R, Wade C, Storm DR. 1998a. Stimulation of cAMP response element (CRE)-mediated transcription during contextual learning. Nat Neurosci 1: 595-601.

Impey S, Obrietan K, Wong ST, Poser S, Yano S, Wayman G, Deloulme JC, Chan G, Storm DR. 1998b. Cross talk between ERK and PKA is required for $\mathrm{Ca}^{2+}$ stimulation of CREB-dependent transcription and ERK nuclear translocation. Neuron 21: 869-883.
Impey S, Fong AL, Wang Y, Cardinaux JR, Fass DM, Obrietan $\mathrm{K}$, Wayman GA, Storm DR, Soderling TR, Goodman RH. 2002. Phosphorylation of CBP mediates transcriptional activation by neural activity and CaM kinase IV. Neuron 34: 235-244.

Leirer VO, Tanke ED, Morrow DG. 1994. Time of day and naturalistic prospective memory. Exp Aging Res 20: 127-134.

Liu FC, Graybiel AM. 1996. Spatiotemporal dynamics of CREB phosphorylation: Transient versus sustained phosphorylation in the developing striatum. Neuron 17: 1133-1144.

Marsicano G, Wotjak CT, Azad SC, Bisogno T, Rammes G, Cascio MG, Hermann H, Tang J, Hofmann C, Zieglgansberger W, et al. 2002. The endogenous cannabinoid system controls extinction of aversive memories. Nature 418: 530-534.

Martin KC, Casadio A, Zhu HX, Yaping E, Rose JC, Chen M, Bailey CH, Kandel ER. 1997. Synapse-specific, long-form facilitation of Aplysia sensory to motor synapses: A function for local protein synthesis in memory storage. Cell 91: 927-938.

Maury P, Queinnec Y. 1992. Influence of time of 24-hour day on depth of processing in recall memory. Br J Psychol 83: 249-260.

Mayford M, Bach ME, Huang YY, Wang L, Hawkins RD, Kandel ER. 1996. Control of memory formation through regulated expression of a CaMKII transgene. Science 274: 1678-1683.

Miller S, Yasuda M, Coats JK, Jones Y, Martone ME, Mayford M. 2002. Disruption of dendritic translation of CaMKII $\alpha$ impairs stabilization of synaptic plasticity and memory consolidation. Neuron 36: 507-519.

Nguyen PV, Kandel ER. 1996. A macromolecular synthesis-dependent late phase of long-term potentiation requiring cAMP in the medial perforant pathway of rat hippocampal slices. J Neurosci 16: 3189-3198.

Phan TH, Chan GC, Sindreu CB, Eckel-Mahan KL, Storm DR. 2011. The diurnal oscillation of MAP (mitogen-activated protein) kinase and adenylyl cyclase activities in the hippocampus depends on the suprachiasmatic nucleus. I Neurosci 31: 10640-10647.

Pineda VV, Athos JI, Wang H, Celver J, Ippolito D, Boulay G, Birnbaumer L, Storm DR. 2004. Removal of $\mathrm{G}_{\mathrm{i} \alpha 1}$ constraints on adenylyl cyclase in the hippocampus enhances LTP and impairs memory formation. Neuron 41: $153-163$.

Pittenger C, Huang YY, Paletzki RF, Bourtchouladze R, Scanlin H, Vronskaya S, Kandel ER. 2002. Reversible inhibition of CREB/ATF transcription factors in region CA1 of the dorsal hippocampus disrupts hippocampus-dependent spatial memory. Neuron 34: 447-462.

Poser S, Storm DR. 2001. Role of $\mathrm{Ca}^{2+}$-stimulated adenylyl cyclases and memory formation. Int J Dev Neurosci 19: 387-394.

Sacktor TC. 2011. How does PKM $\zeta$ maintain long-term memory? Nat Rev Neurosci 12: 9-15.

Shan Q, Chan GC, Storm DR. 2008. Type 1 adenylyl cyclase is essential for maintenance of remote contextual fear memory. J Neurosci 28: 12864-12867.

Sindreu CB, Scheiner ZS, Storm DR. 2007. $\mathrm{Ca}^{2+}$-stimulated adenylyl cyclases regulate ERK-dependent activation of MSK1 during fear conditioning. Neuron 53: 79-89.

Stephan FK, Kovacevic NS. 1978. Multiple retention deficit in passive avoidance in rats is eliminated by suprachiasmatic lesions. Behav Biol 22: $456-462$

Storm DR, Hansel C, Hacker B, Parent A, Linden DJ. 1998. Impaired cerebellar LTP in type I adenylyl cyclase mutant mice. Neuron 20: $1199-1210$.

Sweatt JD. 2010. DNA methylation and memory formation. Nat Neurosci 13: $1319-1323$.

Tapp WN, Holloway FA. 1981. Phase shifting circadian rhythms produces retrograde amnesia. Science 211: 1056-1058.

Taubenfeld SM, Wiig KA, Bear MF, Alberini CM. 1999. A molecular correlate of memory and amnesia in the hippocampus. Nat Neurosci 2: 309-310.

Taubenfeld SM, Wiig KA, Monti B, Dolan B, Pollonini G, Alberini CM. 2001. Fornix-dependent induction of hippocampal CCAAT enhancer-binding protein $\beta$ and $\delta$ co-localizes with phosphorylated cAMP response element-binding protein and accompanies long-term memory consolidation. J Neurosci 21: 84-91.

Taylor JR, Birnbaum S, Ubriana R, Arnsten AF. 1999. Activation of PKA in prefrontal cortex impairs working memory. J Neuro Sci 19: RC23.

Thibault O, Landfield PW. 1996. Increase in single L-type calcium channels in hippocampal neurons during aging. Science 272: 1017-1020.

Toescu EC, Verkhratsky A. 2007. The importance of being subtle: Small changes in calcium homeostasis control cognitive decline in normal aging. Aging Cell 6: 267-273.

Villacres EC, Wong ST, Chavkin C, Storm DR. 1998. Type I adenylyl cyclase mutant mice have impaired mossy fiber long-term potentiation. $J$ Neurosci 18: 3186-3194.

Wang H, Storm DR. 2003. Calmodulin regulated adenylyl cyclases: Crosstalk and plasticity in the central nervous system. Mol Pharm 63: 463-468.

Wang H, Ferguson GD, Pineda VV, Cundiff PE, Storm DR. 2004. Overexpression of type-1 adenylyl cyclase in mouse forebrain enhances recognition memory and LTP. Nat Neurosci 7: 635-642. 
Wang M, Ramos BP, Paspalas CD, Shu Y, Simen A, Duque A, Vijayraghavan S, Brennan A, Dudley A, Nou E, et al. 2007. $\alpha 2 \mathrm{~A}$-Adrenoceptors strengthen working memory networks by inhibiting cAMP-HCN channel signaling in prefrontal cortex. Cell 129: 397-410.

Wong ST, Athos J, Figueroa XA, Pineda VV, Schaefer ML, Chavkin CC, Muglia LJ, Storm DR. 1999. Calcium-stimulated adenylyl cyclase activity is critical for hippocampus-dependent long-term memory and late phase LTP. Neuron 23: 787-798.

Wu ZL, Thomas SA, Villacres EC, Xia Z, Simmons ML, Chavkin C, Palmiter RD, Storm DR. 1995. Altered behavior and long-term potentiation in type I adenylyl cyclase mutant mice. Proc Natl Acad Sci 92: $220-224$.

Wu GY, Deisseroth K, Tsien RW. 2001. Activity-dependent CREB phosphorylation: Convergence of a fast, sensitive calmodulin kinase pathway and a slow, less sensitive mitogen-activated protein kinase pathway. Proc Natl Acad Sci 98: 2808-2813.
Xia ZG, Refsdal CD, Merchant KM, Dorsa DM, Storm DR. 1991. Distribution of mRNA for the calmodulin-sensitive adenylate cyclase in rat brain: Expression in areas associated with learning and memory. Neuron 6: 431-443.

Xia Z, Choi EJ, Wang F, Blazynski C, Storm DR. 1993. Type I calmodulin-sensitive adenylyl cyclase is neural specific. J Neurochem 60: $305-311$.

Yin JCP, Wallach JS, Del Vecchio M, Wilder EL, Zhou H, Quinn WG, Tully T. 1994. Induction of a dominant negative CREB transgene specifically blocks long-term memory in Drosophila. Cell 79: 49-58.

Yin JC, Del Vecchio M, Zhou H, Tully T. 1995. CREB as a memory modulator: Induced expression of a dCREB2 activator isoform enhances long-term memory in Drosophila. Cell 81: 107-115.

Received May 17, 2012; accepted in revised form May 22, 2012. 


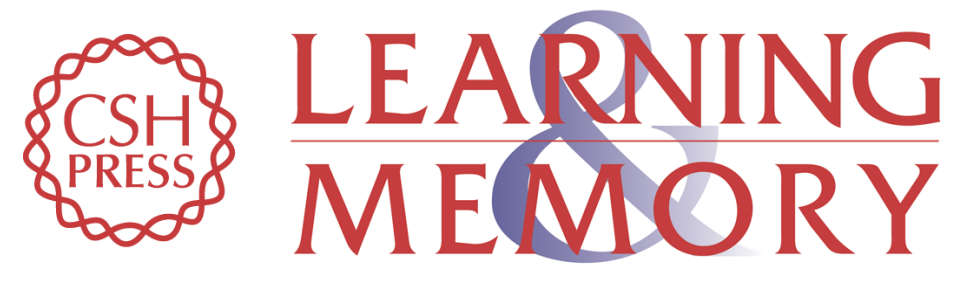

\section{Role of signal transduction crosstalk between adenylyl cyclase and MAP kinase in hippocampus-dependent memory}

Zhengui Xia and Daniel R. Storm

Learn. Mem. 2012, 19:

Access the most recent version at doi:10.1101/lm.027128.112

References This article cites 54 articles, 17 of which can be accessed free at: http://learnmem.cshlp.org/content/19/9/369.full.html\#ref-list-1

License

Email Alerting Receive free email alerts when new articles cite this article - sign up in the box at the Service top right corner of the article or click here. 